\title{
Farmers' Cognition and Behavioral Response towards Cultivated Land Quality Protection in Northeast China
}

\author{
Hongbin Liu ${ }^{1}$ and Yuepeng Zhou ${ }^{2, *(1)}$ \\ 1 College of Land and Environment, Shenyang Agricultural University, Shenyang 110866, China; \\ liuhongbinsy@syau.edu.cn \\ 2 China Centre for Land Policy Research \& College of Public Administration, Nanjing Agricultural University, \\ Nanjing 210095, China \\ * Correspondence: zhouyuepeng@njau.edu.cn; Tel.: +86-025-8439-5700
}

Received: 7 May 2018; Accepted: 7 June 2018; Published: 7 June 2018

\begin{abstract}
The purpose of this paper is to investigate the impacts of farmers' cognition of cultivated land quality protection (CLQP) on their behavioral response to land use practices. To this end, this paper establishes a theoretical framework linking farmers' cognition (on CLQP status, policies and patterns) to their behavioral response (choices of farming methods, land inputs and agricultural waste disposal methods). A field survey was conducted in suburban areas in Liaoning province, Northeast China. A total of 240 households were selected using stratified random sampling. Results show that: (i) in regards to household cognition on CLQP, although a majority of households agree that CLQP is important and have a strong willingness to protect cultivated land quality, their cognition on the future prospect of CLQP is not optimistic; (ii) with regard to household responses to land use practices, a number of households have realized the importance of crop rotation, however, the use of chemical fertilizers is mostly based on past experience and is often excessive. Besides, the disposal of agricultural waste is inappropriate; (iii) household cognition on CLQP policies is found to be the most powerful factor that could lead to an improvement of CLQP practices. It is thus concluded that the government should help households adopt effective farming methods which are environmentally-friendly and sustainable by enhancing publicity of CLQP policies and strengthening farmers' confidence in CLQP.
\end{abstract}

Keywords: cultivated land quality protection (CLQP); farmer's cognition; behavioral response

\section{Introduction}

China underwent rapid urbanization since the Reform and Opening-up policies were initiated in 1978. The urbanization rate, measured by urban population, increased from $17.92 \%$ in 1978 to $57.35 \%$ in 2016 [1]. In the developed regions, such as regions in eastern China, the urbanization rate was up to $87.90 \%$ in Shanghai in 2016. In northeast China, the urbanization rate in Liaoning was $67.37 \%$, which was much higher than the rates in other northeast provinces. Rapid urbanization results in demand for land for urban housing, business and build-up land use. Consequently, much of the cultivated land was converted into non-agricultural land [2]. Numerous urban constructions and industrial parks that occupied former cultivated land increased China's risk of grain supply security and its reliance on imported food products [3,4]. Hence, in response to food security concerns and sustainable agricultural development, the Chinese government has implemented the strictest system of cultivated land protection in the world to maintain the quantity and quality of cultivated land [5,6].

As the basic decision-making units that could directly control land use and management, farm households play an important role in cultivated land protection [7], especially in raising the quality 
of cultivated land [8]. On the one hand, farmers' participation in soil conservation, their choice of sustainable farming methods and their rate of recycling agricultural waste are directly related to cultivated land quality protection (CLQP). On the other hand, according to social cognitive theory, individual behavior could be affected by personal and cognitive factors [9]. In other words, farmers' decisions and behaviors in land use may be determined by the interconnections between cognitive factors (such as thoughts and perception) and action. Biased intuition and cognition may lead to inappropriate behaviors. Cognition may change behavior, and vice versa. Therefore, the study of the impact of farmers' cognition of cultivated land quality on their behavior responses at a micro-perspective is significant for promoting cultivated land quality and has become a hot topic.

Many studies have been conducted to explore the links between individual farmers' behavior and cultivated land protection. Recent land quality studies mainly focus on three aspects: the role farmers play on cultivated land conservation [10,11], the factors affecting farmer's behavior on cultivated land conservation [8,12], and suggestions for improving farmers' incentives on cultivated land protection [13]. These studies have provided insights into the contribution of farmer behavior on cultivated land protection. However, there is room for improvement. Farmers are decision-makers in a complex system of cause and effect. They make decisions with respect to their own attitude and beliefs and according to their farm structure, and they take into account programs and regulations of the overarching policy scheme [14]. This has been supported by the study of Bijani et al. [15] who found that the variables "attitude towards soil conservation", "social pressures on soil conservation" and "soil conservation concern" have significant effects on "soil conservation behavior" in Iran. Some studies in China have paid attention to the impacts of farmer attitudes and cognition on their behavior response on environmental protection [16], rural living environment improvement [17], and village agglomeration [18]. However, how does farmers' attitude and perception on cultivated land protection policies and status affect their decision-making in relation to land conservation behavior is still unclear in rural China. To fill this gap, a conceptual framework linking farmers' cognition of cultivated land protection to their behavioral response has been constructed in this study. Survey data of 238 farm households from Sujiatun district, Shenyang city, Liaoning province has been used. In addition to the potential contribution to theory, this study may also provide evidence on how to guide farmers to use cultivated land appropriately and improve land quality in similar areas.

\section{Conceptual Framework}

Based on the theory of environmental psychology and the theory of cognition and behavior, Kollmuss and Agyeman [19] built a framework presenting the factors affecting pro-environmental behavior, including "incentives for pro-environmental behavior", "environmental attitudes and values" and "feasibility of pro-environmental measures". Accordingly, in the field of cultivated land protection behavior, the knowledge of cultivated land protection forms individual farmers' cognition and attitude towards cultivated land conservation, which in turn leads to their decision-making and behavioral responses. Based on advice from experts of soil science, experts of agricultural technology, and surveyed farmers, in this study, we define cognition of cultivated land quality as an intuitional and presentative perception, which includes farmers' cognition on land quality condition, related policies, motivation and methods of cultivated land conservation. We also define behavioral response of decision making as behavior that is highly connected to change land quality, including modes of land use, modes of land inputs and modes of waste disposal.

The procedure of land use could be divided into the decision-making unit and the land use unit, which affects farmers' decision-making and land quality change. Cultivated land serves two functions, namely, grain production function and value store function. The change of cultivated land quality determines the capacity of grain production and value store. As Figure 1 shows, in order to promote land's grain production capacity, farmers would adjust their decision-making on land use in accordance with their cognition on cultivated land quality protection. Specifically, farmers would adjust their choices of farming methods, land inputs and waste disposal methods on the basis of their 
cognition on cultivated land quality protection status, policies, willingness, and protection methods. Their choices of farming methods, land inputs and waste disposal methods would in turn affect land use patterns and directly lead to land quality change. In this process, in order to maximize utility, farmers would adjust their decision-making on land use according to their cognition differences in cultivated land quality protection, and thus make the land's food production function and value store function meet their demand.

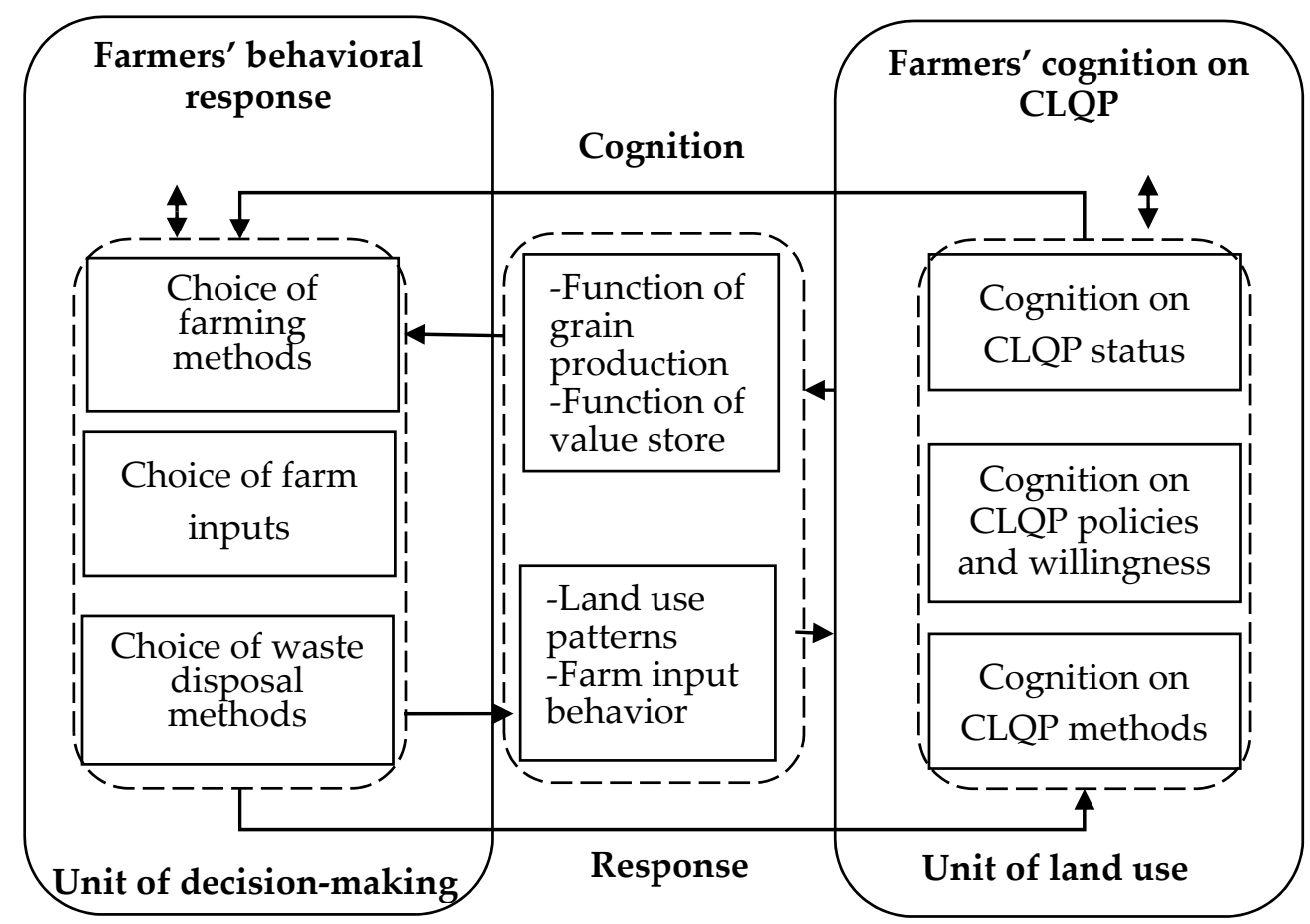

Figure 1. The process of "cognition-decision making-behavioral response-cognition" of the households towards cultivated land quality protection (CLQP).

\section{Materials and Methods}

\subsection{Study Sites and Samples}

This study was conducted in Sujiatun district of Shenyang city, Liaoning province. According to the distance to the city center of Sujiatun, as is shown in Figure 2, Linhu street (suburb), Wanggangbao town (middle) and Yongle town (outer suburb) have been further selected for the following reasons: First, the study sites are located in the middle area of Liaohe Plain and Shenyang economic zone, where the conflict between cultivated land quality protection and socio-economic development is prominent. Second, the study sites are the main supply locations of vegetables and fruits for Shenyang city. Thus, cultivated land quality protection is important for farm product outputs and food security. Third, the study sites have been strongly affected by industrialization and urbanization. Farmers in different areas are influenced by different socio-economic contexts, which would lead to different cognition on cultivated land quality protection. As a result, the selection of study sites is representative.

After the selection of study sites, our research team conducted a field survey in July-August 2015. Based on the town size, a number of villages and households were selected randomly in each town. Data was collected via a questionnaire which covered household characteristics, household cognition on cultivated land quality protection, and household behavioral response. A total of 240 questionnaires have been collected. By excluding 2 invalid questionnaires, the sample was further reduced to 238 observations. 


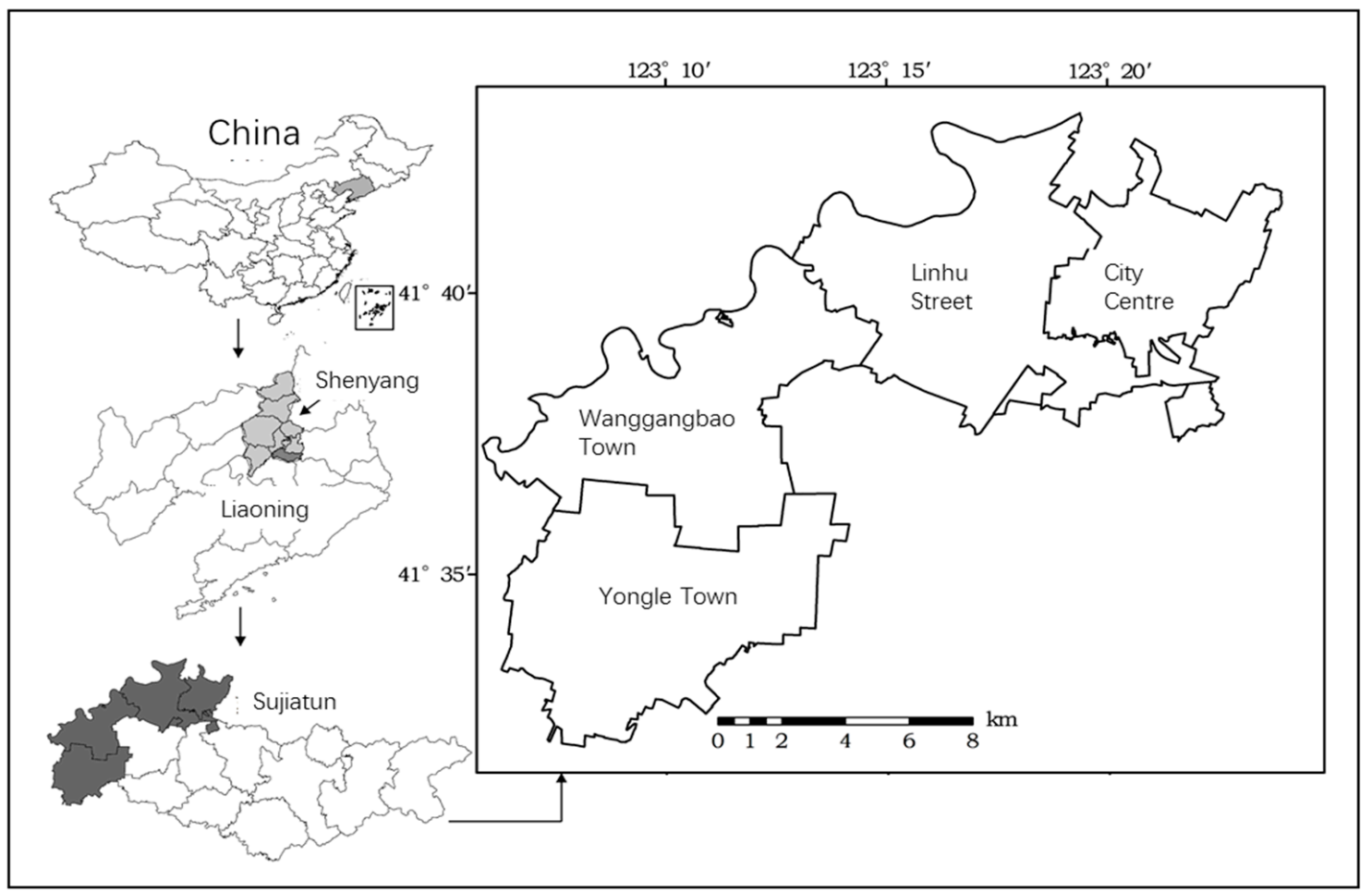

Figure 2. Geographical location of study sites.

\subsection{Model Specification and Evaluation Criteria}

In order to test the abovementioned framework, variables related to a farmer's decision-making in the process of cultivated land quality protection are considered as dependent variables, including the choice of farming methods, choice of farm inputs, and choice of waste disposal methods. Each variable is combined by several indicators, which are quantized and assigned a value between $0-1$. The higher the value, the more beneficial to cultivated land quality protection.

The key independent variables are the farmer's cognition of cultivated land quality protection, including the farmer's cognition of the status, policies, and willingness of the cultivated land quality protection. Similarly, each variable is combined by several indicators.

For analyzing the impact of farmer's cognition on their decision-making in cultivated land quality protection, three models are used, giving as follows:

$$
\operatorname{Cog} n=f(\mathrm{CPJ}, \mathrm{CCW}, \mathrm{CCP})
$$

Model 1 describes farmer's cognition $(\operatorname{Cog} n)$ on cultivated land quality protection, which is combined by farmer's cognition and judgement on CLQP status (CPJ), cognition on CLQP policies (CCW), and cognition on CLQP patterns (CCP) (see Table 1).

- $\quad$ CPJ: Two indicators are used to represent CPJ: (i) farmer's standard to judge land quality (1-thick soil layer without hardening, 0.5 - high output, or 0 - unknown); and (ii) whether farmers keep an eye on land quality change ( 1 -yes, 0.5 -do not care, 0 -no).

- CCW: Four indicators are used to stand for CCW: (i) whether farmers regard cultivated land quality protection as important (1-very important, 0.5 -important but cannot be overemphasized, 0 -not important); (ii) whether farmers are willing to protect cultivated land quality (1-yes, $0-$ no); (iii) perception on prospect of cultivated land quality protection (1-optimistic, 0.5-medium, 0-pessimistic); and (iv) who are the main responsibility person in cultivated land quality protection ( 1 -farm households, 0 - the central and local governments). 
- CCP: Two indicators are used to represent CCP: (i) farmers' cognition on the methods that may improve land quality ( 1 -use manure, 0.5 -use household excrement, 0.5 -crop rotation, 0 - unknown); and (ii) farmers' cognition of the function of fertilizers (1-moderate fertilization could improve land quality, 0.5 - excessive fertilization is a waste, 0 - the increase of output entirely depends on the application of fertilizers).

The behavioral response equation is given by:

$$
\text { Beha }=f(\text { CLM, LIM, AWTM })
$$

Model 2 describes farmers' behavior related to cultivated land quality protection, including the choice of farming methods (CLM), the choice of land inputs (LIM), and the choice of agricultural waste disposal methods (AWTM) (see Table 2).

- CLM: The indicator representing CLM is whether farmers would consider crop rotation on the same plot (1-yes, 0 -no).

- LIM: Three indicators are used to stand for LIM: (i) use of manure and fertilizers (1—only manure, 0.5-both manure and fertilizers, 0 - only fertilizers); (ii) the decision on how much manure and fertilizers to be used is based on ... ? (1—soil fertility, 0.5 - crop variety, 0.5 -output in previous year, 0 -personal experience); (iii) the use of pesticides is based on ... ? (1-status of pests and diseases, 0.5 -crop variety, 0 - personal experience).

- AWTM: Two indicators are used to represent AWTM: (i) disposal of plastic film residue (1-recycling of the large piece of residue, 0.5 - only small pieces of residue have been collected and disposed, 0 -all plastic film residue has been left in the soil); and (ii) disposal of crop stalks (1—return to field, 0.5—used as fuel, 0.5—-discarded, 0— burned in the field).

The assignment of scores is based on the study of Wang and $\mathrm{Gu}$ [16] on farmer cognition and behavior response on environmental protection. Combining model 1 and 2, model 3 which tests the impacts of farmer cognition on behavior can be specified as:

$$
\text { Beha }=f(\mathrm{CLM}, \mathrm{LIM}, \mathrm{AWTM})=g(\operatorname{Cog} n)=g[f(\mathrm{CPJ}, \mathrm{CCW}, \mathrm{CCP})]=h(\mathrm{CPJ}, \mathrm{CCW}, \mathrm{CCP})
$$

In order to capture the complex mechanism regarding farmers' cognition and behavior, we employ simultaneous equations among models 1-3. In addition, some unobservable variables should be controlled. As a result, model 4 which can be expressed as a multiple linear regression model is estimated by:

$$
\text { Beha }=\alpha_{0}+\alpha_{1} \mathrm{CPJ}+\alpha_{2} \mathrm{CCW}+\alpha_{3} \mathrm{CCP}+u_{i}
$$

where $u_{i}$ stands for random error term.

\section{Results and Discussion}

\subsection{Farmers' Cognition on $C L Q P$}

Table 1 reports farmer cognition on cultivated land quality protection. Regarding farmer cognition and judgement on CLQP status, $45.80 \%$ of households take "thick soil layer without hardening" (means that the soil layer is thick, and the surface layer of the soil is not hardening and impervious) as the standard to evaluate the quality level of land, while $43.28 \%$ of households take "high output" as the standard. $87.40 \%$ of households have kept an eye on land quality change. These figures show that most farmers pay close attention to land quality but present some difference in judgement standard.

In terms of farmer cognition on CLQP policies, $85.55 \%$ of households regard cultivated land quality protection as "very important", which means most farmers have realized the importance of CLQP. Although $98.32 \%$ of households are willing to protect land quality, farmers' perception on the prospect of cultivated land quality protection is not so positive. Only $10.08 \%$ of households are 
optimistic and the others are skeptical. Around $2 / 3$ of households agree that farmers per se (rather than the government) are the main responsibility party in cultivated land quality protection. This means that most farmers have realized their roles in CLQP and are willing to contribute, but they also have perceived the pressure and dilemma of CLQP.

Concerning farmer cognition on CLQP patterns, $92 \%$ of households deem that the use of manure could improve land quality. However, as most households do not raise poultry, the attainment and use of manure requires more efforts such as additional time and financial investments. Nearly half of households agree that moderate fertilization could improve land quality. $27.73 \%$ of households consider excessive fertilization is a waste which could lead to the rise of cost and waste of fertilizers. Still $23.95 \%$ of households firmly believe that the increase of output and improvement of land quality entirely depend on the application of fertilizers. These figures indicate that most farmers are rational. However, as to some farmers, without knowing exactly how much fertilizers should be used, it is almost certainly that they would apply fertilizers excessively in order to guarantee the output.

Table 1. Farmers' cognition on cultivated land quality protection (CLQP).

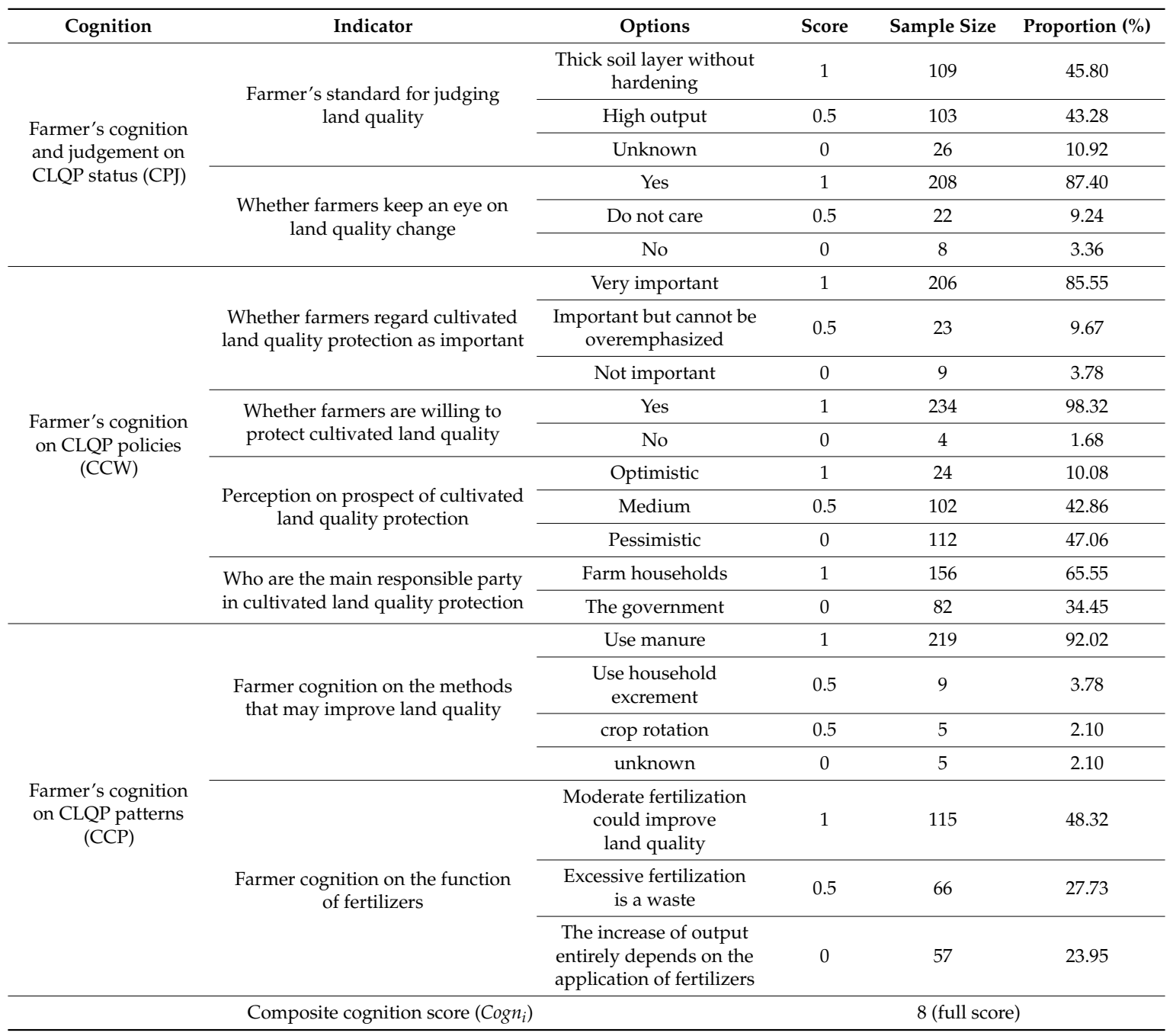

The composite cognition score of each household is the total sum of all indicators, with the full score valued at 8 . As is shown in Figure 3, about 133 households (56\%) scored between 6-7 and the mode is 6.5 (50 households, $21 \%$ ). This indicates that, in the study sites, the overall cognition level on CLQP is relatively high. 


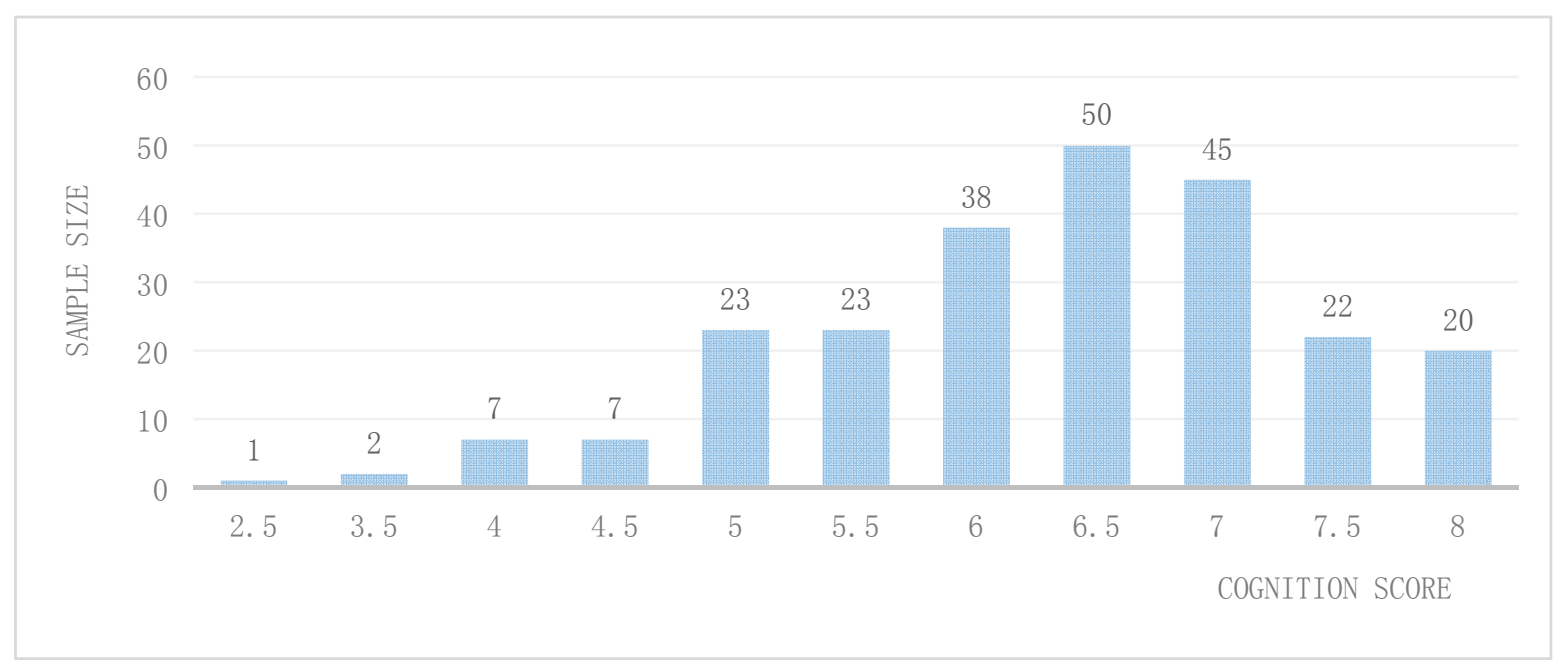

Figure 3. Frequency distribution of household cognition scores $\left(\operatorname{Cog} n_{i}\right)$ on cultivated land quality protection (CLQP).

\subsection{Farmers' Behavioral Response on CLQP}

Table 2 describes farmers' behavioral responses on cultivated land quality protection.

Table 2. Farmers' behavioral response on cultivated land quality protection (CLQP).

\begin{tabular}{|c|c|c|c|c|c|}
\hline $\begin{array}{l}\text { Behavioral } \\
\text { Response }\end{array}$ & Indicator & Options & Score & Sample Size & Proportion $(\%)$ \\
\hline $\begin{array}{l}\text { Choice of farming } \\
\text { methods (CLM) }\end{array}$ & $\begin{array}{l}\text { Whether farmers would consider } \\
\text { crop rotation on the same plot }\end{array}$ & Yes & 1 & 128 & 53.78 \\
\hline \multirow{7}{*}{$\begin{array}{l}\text { Choice of land inputs } \\
\text { (LIM) }\end{array}$} & \multirow[b]{2}{*}{ Use of manure and fertilizers } & Manure only & 1 & 6 & 2.52 \\
\hline & & $\begin{array}{l}\text { Both manure and } \\
\text { fertilizers }\end{array}$ & 0.5 & 118 & 49.58 \\
\hline & \multirow{4}{*}{$\begin{array}{l}\text { Decision on how much manure and } \\
\text { fertilizers to be used is based on ...? }\end{array}$} & Soil fertility & 1 & 31 & 13.03 \\
\hline & & Crop variety & 0.5 & 26 & 10.92 \\
\hline & & Output in previous year & 0.5 & 10 & 4.20 \\
\hline & & Personal experience & 0 & 171 & 71.85 \\
\hline & Use of pesticides is based on ...? & Personal experience & 0 & 80 & 33.62 \\
\hline \multirow{5}{*}{$\begin{array}{l}\text { Choice of } \\
\text { agricultural waste } \\
\text { disposal methods } \\
\text { (AWTM) }\end{array}$} & \multirow{3}{*}{ Disposal of plastic film residue } & $\begin{array}{l}\text { Recycling of the large } \\
\text { piece of residue }\end{array}$ & 1 & 146 & 61.34 \\
\hline & & $\begin{array}{l}\text { Only small pieces of } \\
\text { residue have been } \\
\text { collected and disposed }\end{array}$ & 0.5 & 48 & 20.17 \\
\hline & & $\begin{array}{l}\text { All plastic film residue } \\
\text { has been left in the soil }\end{array}$ & 0 & 44 & 18.49 \\
\hline & \multirow{2}{*}{ Disposal of crop stalks } & Return to field & 1 & 10 & 4.20 \\
\hline & & Used as fuel & 0.5 & 158 & 66.39 \\
\hline
\end{tabular}


As to the choice of farming methods, $53.78 \%$ of households consider the option of crop rotation on the same plot, which is helpful to improve land quality. Regarding the choice of land inputs, more than $70 \%$ of farmers apply fertilizers according to their experience, rather than soil fertility, crop variety and the output in previous year. The major fertilizers used are chemical fertilizers or a mixed of chemical fertilizers with manure. Only 6 households stated that they use manure only. The response on fertilizer use implies that a scientific guidance of fertilizing is missing in the study sites. The application of pesticides is more appropriate than fertilizer use. There are 148 households $(62 \%)$ who tend to decide the usage of pesticides by judging the status of pests and diseases.

In terms of the choice of agricultural waste disposal methods, $61 \%$ of households are inclined to recycle the large pieces of residue. However, $18 \%$ still choose to leave the residue on the plots. Farmer incentives to recycle plastic film residue need to be stimulated.

The return of crop stalks to field has been regarded as a good way to improve land quality. However, only 10 households choose to do so. The disposal of crop stalks still follows traditional practices. Thus, innovative crop stalks decomposing technologies and returning practices are needed to reduce the use of chemical fertilizers, improve long-term productive capacity of soil resources, and assure a sustainable agricultural development.

Similar to the cognition score, the composite response score of each household is the total sum of all indicators, with the full score valued at 6. As is shown in Figure 4, about 117 households (46\%) scored between 3-4 and the mode is 3.5. There are 86 households who scored below 3 , this indicates that, in the study sites, the overall response level on CLQP is relatively low.

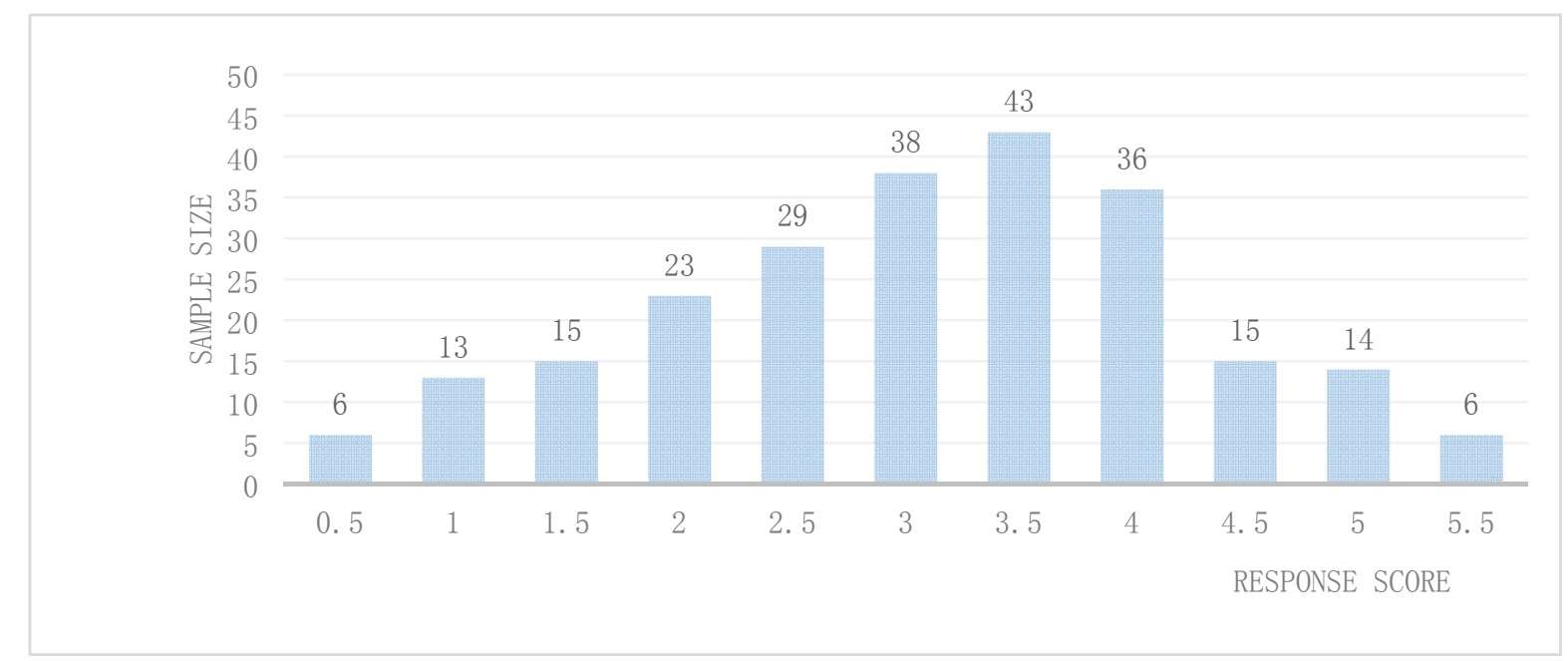

Figure 4. Frequency distribution of household behavioral response score $\left(B e h a_{i}\right)$ on cultivated land quality protection (CLQP).

\subsection{Consistency between Cognition and Behavioral Response: A Preliminary Test}

In order to explore the relationship between farmers' cognition and behavioral response on cultivated land quality protection, let $X_{i}\left(\operatorname{Cog} n_{i}, B e h a_{i}\right)$ stand for household $i$ 's cognition and behavioral response, respectively. As is shown in Figure 5, in Yongle town and Wanggangbao town, there is a synchronous fluctuation between cognition and behavioral response, which means farmer cognition and behavioral response on CLQP is correlated in these two areas.

Specifically, the correlation of cognition and response (r) for the total sample is 0.311 (normally, $|\mathrm{r}|<0.3$ : uncorrelated, $0.3 \leq|\mathrm{r}|<0.5$ : low correlation, $0.5 \leq|\mathrm{r}|<0.8$ : medium correlation, $|\mathrm{r}| \geq 0.8$ : high correlation.). The correlation is stronger in Yongle town (0.555) than in Wanggangbao town (0.363). The relationship is more random in Linhu street, with a much lower correlation coefficient (only 0.083). The preliminary test indicates that there is an interaction between cognition and response in Yongle 
and Wanggangbao towns, which provides evidence to our conceptual framework. The difference may be that in Yongle town, vegetables are the major crop and farm income is the main source of household income. Consequently, households in Yongle pay more attention to cultivated land quality protection. The consistency between cognition and behavioral response on CLQP is higher. However, in Linhu street, maize is the major crop which saves much labor and time. Besides, a large number of households in Linhu street engage in non-agricultural work as Linhu is closer to city. Therefore, households in Linhu would not invest much of their labor force and capital in CLQP. As a result, the correlation between cognition and response is very weak.

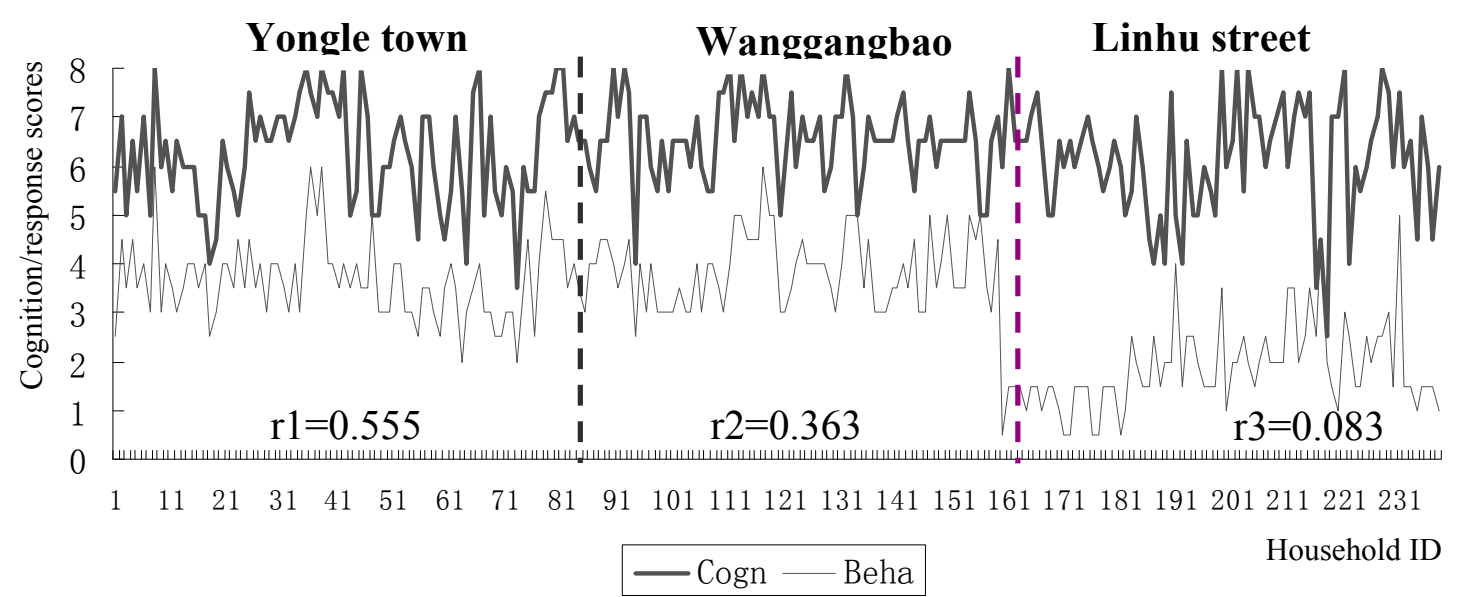

Figure 5. The correlation between farmers' $\operatorname{cognition}\left(\operatorname{Cog} n_{i}\right)$ and behavioral response $\left(B e h a_{i}\right)$ on cultivated land quality protection (CLQP).

\subsection{Empirical Results}

Table 3 reports the regression results of the impact of farmer cognition on their behavioral response of CLQP. Overall, farmer cognition and judgement on CLQP status (CPJ) and cognition on CLQP policies (CCW) have positive and significant effects on CLQP behaviors. The CPJ and CCW increase by 1 , the choice of farming methods (CLM), the choice of land inputs (LIM), and the choice of agricultural waste disposal methods (AWTM) would increase by $0.091,0.082$, and 0.067 , respectively. CCW affects both CLM and LIM, which implies that improving farmers' cognition on policies is the key to promote land quality.

From the perspective of regional difference, farmer cognition shows no impact on response in Linhu street, which is consistent with the preliminary test. In Yongle town, farmer choices of farming methods (CLM) are affected by all three indicators of farmer cognition. The CPJ, CCW, and CCP increase by one unit, CLM would increase by $0.091,0.073$, and 0.145 , respectively. The choice of land inputs (LIM) and the choice of agricultural waste disposal methods (AWTM) are more affected by CCP and CPJ, respectively. The CCP and CPJ increase by one unit, LIM and AWTM would increase by 0.610 he 0.156 , respectively. Thus, farmer's cognition and judgement on CLQP status (CPJ), cognition on CLQP policies (CCW), and cognition on CLQP patterns (CCP) are all important factors determining farmer's choice of CLQP way, particularly the farming methods. In Wanggangbao town, only farmers' cognition on CLQP policies (CCW) presents positive and significant impact on response. With CCW increases by one unit, the LIM and AWTM would increase by 0.472 and 0.142 , correspondingly. This indicates that the major step to improve land quality would be to improve farmer cognition on CLQP policies. 
Table 3. Impacts of farmer cognition components on behavioral response components.

\begin{tabular}{|c|c|c|c|c|c|}
\hline \multirow{2}{*}{ Region } & \multirow{2}{*}{\multicolumn{2}{|c|}{ Independent Variables ${ }^{a}$}} & \multicolumn{3}{|c|}{ Dependent Variables $^{b}$} \\
\hline & & & CLM & LIM & AWTM \\
\hline \multirow{3}{*}{ Total } & $\mathrm{CPJ}$ & $\begin{array}{c}\text { Coef. } \\
t \text {-value }\end{array}$ & & & $\begin{array}{c}0.067^{*} \\
1.992\end{array}$ \\
\hline & $\mathrm{CCW}$ & $\begin{array}{c}\text { Coef. } \\
t \text {-value }\end{array}$ & $\begin{array}{c}0.091^{* *} \\
2.202\end{array}$ & $\begin{array}{c}0.082 \text { * } \\
1.347\end{array}$ & \\
\hline & $\mathrm{CCP}$ & $\begin{array}{l}\text { Coef. } \\
t \text {-value }\end{array}$ & & & \\
\hline \multirow{3}{*}{ Yongle town } & $\mathrm{CPJ}$ & $\begin{array}{c}\text { Coef. } \\
t \text {-value }\end{array}$ & $\begin{array}{c}0.091 * \\
1.362\end{array}$ & & $\begin{array}{c}0.156 \text { * } \\
1.381\end{array}$ \\
\hline & CCW & $\begin{array}{c}\text { Coef. } \\
t \text {-value }\end{array}$ & $\begin{array}{c}0.073 \text { * } \\
1.896\end{array}$ & & \\
\hline & СCP & $\begin{array}{c}\text { Coef. } \\
t \text {-value }\end{array}$ & $\begin{array}{c}0.145^{* *} \\
1.355\end{array}$ & $\begin{array}{c}0.610^{* * * *} \\
3.199\end{array}$ & \\
\hline \multirow{3}{*}{ Wanggangbao town } & $\mathrm{CPJ}$ & $\begin{array}{c}\text { Coef. } \\
t \text {-value }\end{array}$ & & & \\
\hline & $\mathrm{CCW}$ & $\begin{array}{c}\text { Coef. } \\
t \text {-value }\end{array}$ & & $\begin{array}{c}0.472 * \\
2.586\end{array}$ & $\begin{array}{c}0.142 * \\
1.502\end{array}$ \\
\hline & $\mathrm{CCP}$ & $\begin{array}{c}\text { Coef. } \\
t \text {-value }\end{array}$ & & & \\
\hline \multirow{3}{*}{ Linhu street } & CPJ & $\begin{array}{c}\text { Coef. } \\
t \text {-value }\end{array}$ & & & \\
\hline & CCW & $\begin{array}{c}\text { Coef. } \\
t \text {-value }\end{array}$ & & & \\
\hline & $\mathrm{CCP}$ & $\begin{array}{l}\text { Coef. } \\
t \text {-value }\end{array}$ & & & \\
\hline
\end{tabular}

Note: ${ }^{* * *} 1 \%, * * 5 \%$, and ${ }^{*} 10 \%$. Only significant coefficients are reported. ${ }^{\text {a }}$ Independent variables refer to farmer cognition on cultivated land quality protection (CLQP), including: CPJ—farmer cognition and judgement on CLQP status; CCW - farmers' cognition on CLQP policies, and CCP-farmers' cognition on CLQP patterns; ${ }^{b}$ Dependent variables refer to farmers' behavioral response on cultivated land quality protection (CLQP), including: CLM - the choice of farming methods, LIM — the choice of land inputs, and AWTM — the choice of agricultural waste disposal methods.

\section{Conclusions and Policy Implication}

On the basis of our conceptual framework and survey data, the main findings of this study are as follows. (i) From the perspective of the cognition on cultivated land quality protection (CLQP), farmers in city suburbs generally regard cultivated land quality protection as important and they have a strong willingness to contribute to CLQP. They are also able to judge the level of land quality and identify the responsibility entity and measures of CLQP; (ii) From the perspective of farmer behavioral responses on CLQP, farmers have realized the importance of crop rotation. However, chemical fertilizers are the major inputs and the usage is mainly based on personal experience rather than scientific guidance, which often leads to excessive use of chemical fertilizers. The disposal of plastic films and crop stalks is also lack of scientific guidance; (iii) There are some causal effects between farmer cognition and behavioral responses on CLQP. Regional difference also leads to different results.

There are some policy implications on cultivated land quality protection. First, farmers in city suburbs have low expectations of CLQP prospects, which would in turn hinder their responses on CLQP. Therefore, the government should take steps to change farmers' pessimistic expectations, including policy support, media publicity, and so on. Second, although some farmers have strong willingness to protect land quality, they do not have adequate ability and technical knowledge and 
could not achieve the optimal results. Thus, departments relating to agricultural technology promotion should endeavor to help farmers by spreading appropriate agricultural technologies and scientific methods of fertilizing. Last but not least, farmer cognition on CLQP policies (CCW) is proved to be the most effective factor that could contributes to response on CLQP. Therefore, it is a priority to improve farmers cognition on CLQP policies, including strengthening publicity and education and raise the comparative revenue of agricultural production.

Despite the potential contribution, our study also suffers from the deficiency of a cross-sectional dataset which was collected in one region-the Sujiatun district of Shenyang city. Our study suggests that further research is necessary to provide more representative datasets and investigate the factors affecting farmers' participation in cultivated land quality protection practices.

Author Contributions: H.L. and Y.Z. conceived and designed the experiments; H.L. collected and analyzed the data; Y.Z. and H.L. wrote the paper.

Acknowledgments: Financial support for this paper has been gratefully received from the National Natural Science Foundation of China (71503174, 71373127 and 71503113), Social Science Planning Foundation of Liaoning Province (L15BJY037), Foundation for Young Scientific and Innovative Talents in Agriculture in Liaoning Province (2015049), and Foundation for Young Scientific and Innovative Talents in Shenyang City (RC170180).

Conflicts of Interest: The authors declare no conflict of interest.

\section{References}

1. National Bureau of Statistics of China. Statistical Yearbook of China; China Statistical Publisher House: Beijing, China, 2017.

2. Deng, X.; Huang, J.; Rozelle, S.; Zhang, J.; Li, Z. Impact of urbanization on cultivated land changes in China. Land Use Policy 2015, 45, 1-7. [CrossRef]

3. Wu, Y.; Zhang, X.; Skitmore, M.; Song, Y.; Hui, E.C.M. Industrial land price and its impact on urban growth: A Chinese case study. Land Use Policy 2014, 36, 199-209. [CrossRef]

4. Liang, C.; Jiang, P.; Wei, C.; Li, M.; Wang, L.; Yuan, G.; Yuzhe, P.; Nan, X.; Duan, Y.; Huang, Q. Farmland protection policies and rapid urbanization in China: A case study for Changzhou City. Land Use Policy 2015, 48, 552-566. [CrossRef]

5. Liu, X.; Zhao, C.; Song, W. Review of the evolution of cultivated land protection policies in the period following China's reform and liberalization. Land Use Policy 2017, 67, 660-669. [CrossRef]

6. Lichtenberg, E.; Ding, C. Chapter 5: Assessing Farmland Protection Policy in China. Land Use Policy 2008, 25, 59-68. [CrossRef]

7. Luo, X.; Zhang, L.; Zhu, Y. Food Security based on Cultivated Land Pressure Index. Chin. Rural Econ. 2016, 2, 83-96. (In Chinese)

8. Chen, J.; Yu, Z.; Ouyang, J.; Mensvoort, M.E.F.V. Factors affecting soil quality changes in the North China Plain: A case study of Quzhou County. Agric. Syst. 2006, 91, 171-188. [CrossRef]

9. Yazdanpanah, M.; Feyzabad, F.R.; Forouzani, M.; Mohammadzadeh, S.; Burton, R.J.F. Predicting farmers' water conservation goals and behavior in Iran: A test of social cognitive theory. Land Use Policy 2015, 47, 401-407. [CrossRef]

10. Sklenicka, P. Classification of farmland ownership fragmentation as a cause of land degradation: A review on typology, consequences, and remedies. Land Use Policy 2016, 57, 694-701. [CrossRef]

11. Chang, H.H.; Mishra, A.K.; Livingston, M. Agricultural policy and its impact on fuel usage: Empirical evidence from farm household analysis. Appl. Energy 2011, 88, 348-353. [CrossRef]

12. Saenz, M.; Thompson, E. Gender and Policy Roles in Farm Household Diversification in Zambia. World Dev. 2017, 89, 152-169. [CrossRef]

13. Zhang, W.; Wang, W.; Li, X.; Ye, F. Economic development and farmland protection: An assessment of rewarded land conversion quotas trading in Zhejiang, China. Land Use Policy 2014, 38, 467-476. [CrossRef]

14. Celio, E.; Flint, C.G.; Schoch, P.; Grêt-Regamey, A. Farmers' perception of their decision-making in relation to policy schemes: A comparison of case studies from Switzerland and the United States. Land Use Policy 2014, 41, 163-171. [CrossRef] 
15. Bijani, M.; Ghazani, E.; Valizadeh, N.; Haghighi, N.F. Pro-environmental analysis of farmers' concerns and behaviors towards soil conservation in central district of Sari County, Iran. Int. Soil Water Conserv. Res. 2017, 5, 43-49. [CrossRef]

16. Wang, C.; Gu, H. Farmers' perception of enviroment, behavior decision and the check of consistency between them: An empirical analysis based on the survey of farmers in Jiangsu province. Resour. Environ. Yangtze Basin 2012, 21, 1204-1208. (In Chinese)

17. Deng, Z.; Zhang, J.; Xu, Z. Study on households' cognition and behavior in the improvement of rural environment. Agric. Technol. Econ. 2013, 2, 72-79. (In Chinese)

18. Ye, Q.; Wang, C. Cognition and its impact factors on the scale effects of village agglomeration based on the structural equation model: Taking Chongqing as Example. China Land Sci. 2015, 29, 82-89. (In Chinese)

19. Kollmuss, A.; Agyeman, J. Mind the Gap: Why do people act environmentally and what are the barriers to pro-environmental behavior? Environ. Educ. Res. 2002, 8, 239-260. [CrossRef]

(C) 2018 by the authors. Licensee MDPI, Basel, Switzerland. This article is an open access article distributed under the terms and conditions of the Creative Commons Attribution (CC BY) license (http://creativecommons.org/licenses/by/4.0/). 